\title{
Large-size intramuscular nodular fasciitis, a challenging histopathologic diagnosis confirmed by molecular detection of USP6 gene rearrangement: A case report and literature review
}

\section{Changrong Wang}

Affiliated Hangzhou First People's Hospital Zhejiang University School of Medicine

https://orcid.org/0000-0001-9540-7089

\section{Wei Wang}

Affiliated Hangzhou First People's Hospital Zhejiang University School of Medicine: Hangzhou First

People's Hospital

\section{Rujun Xu}

Affiliated Hangzhou First People's Hospital Zhejiang University School of Medicine: Hangzhou First People's Hospital

Jingjing Xiang ( $\square$ xiang_cell@163.com )

Zhejiang University School of Medicine, Hangzhou, Zhejiang Province https://orcid.org/0000-00022195-9726

\section{Case Report}

Keywords: intramuscular nodular fasciitis, nodular fasciitis, NF, USP6

Posted Date: January 13th, 2021

DOI: https://doi.org/10.21203/rs.3.rs-141423/v1

License: (c) (i) This work is licensed under a Creative Commons Attribution 4.0 International License. Read Full License 


\section{Abstract}

Background: The intramuscular subtype of nodular fasciitis (NF) is rare with lesions normally not more than $2 \mathrm{~cm}$ in size and characterized by pseudosarcomatous morphology.

Case presentation: Here, we report a case of a 27-year-old man presenting with a chief complaint of an increasingly enlarged mass of the left upper arm for 4 months. Magnetic resonance imaging confirmed the presence of a well-defined tumor measuring $5 \mathrm{~cm}$ within the outer edge of the middle humerus. Microscopically, the neoplasm was highly cellular with focally discohesive and myxoid features. In more cellular areas, cells grew in bundles with an interlaced pattern. The mitotic index was high and multinuclear giant cells were evident. The stroma contained collagen with erythrocyte extravasation. The tumor border was infiltrative. Immunohistochemically, the tumor cells were positive for SMA and negative for CK, desmin, CD34, S100, ALK, and $\beta$-catenin. Molecular detection demonstrated evidence of USP6 gene rearrangement in this tumor. Based on the findings, we diagnose this case as intramuscular NF. At 48 months after the initial surgery, the patient had recovered well with no evidence of recurrence or metastasis.

Conclusions: In this study, the diagnosis of intramuscular NF with a relatively large tumor was confirmed by molecular detection of USP6 gene rearrangement.

\section{Full Text}

This preprint is available for download as a PDF.

\section{Tables}

Due to technical limitations, table 1 is only available as a download in the Supplemental Files section.

\section{Figures}




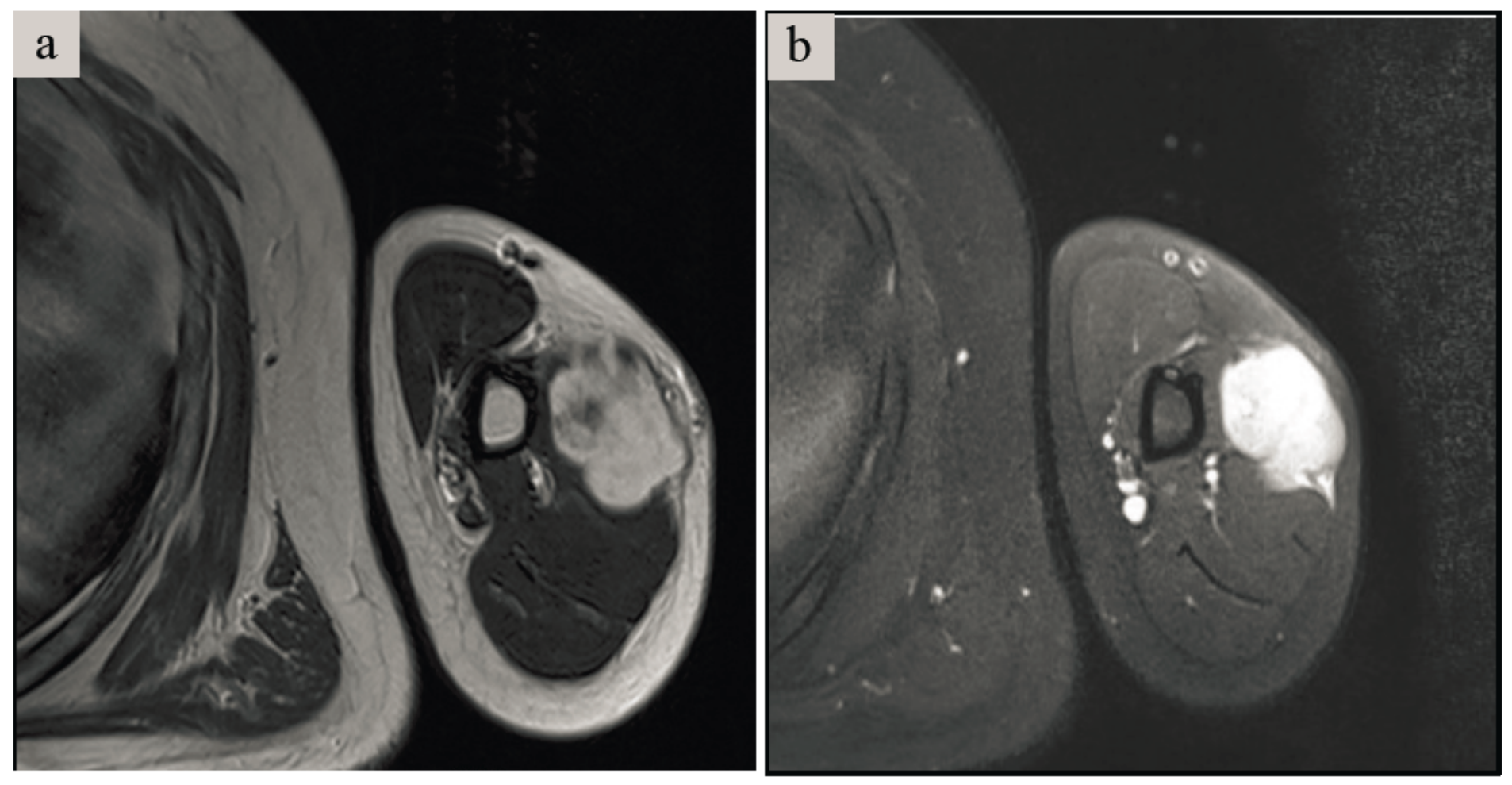

\section{Figure 1}

MRI revealed an irregularly well-defined nodule at the outer edge of the middle humerus. a. The nodule had slightly enhanced signal intensity on T1-weighted imaging. b. On T2-weighted imaging, there was significantly enhanced heterogeneous high signal intensity. 

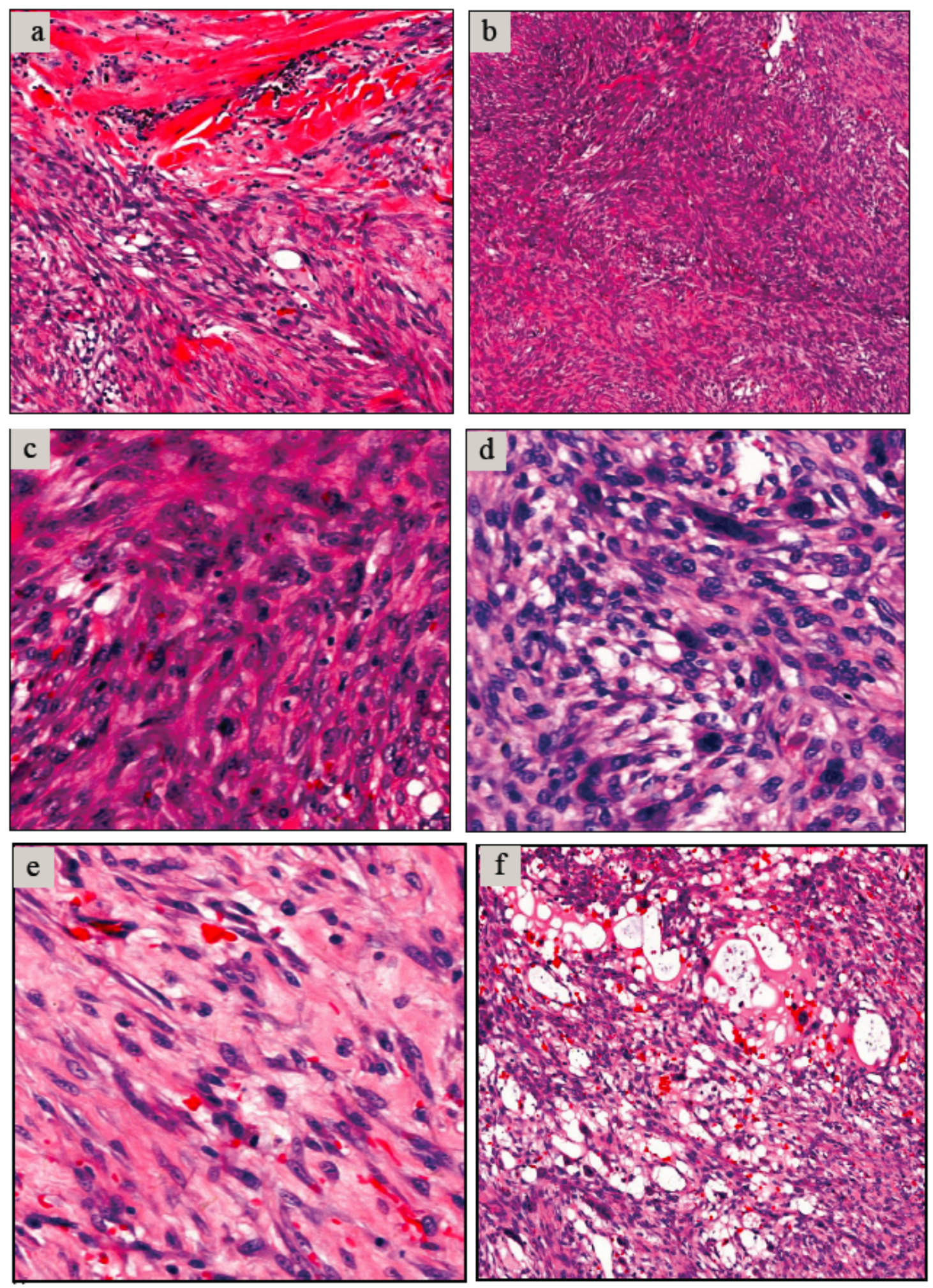

Figure 2

Histopathological findings. Hematoxylin-eosin (HE) staining. a. Tumor cells infiltrating into the surrounding skeletal muscle $(\times 100)$. b. Tumor cells arranged in an interlaced pattern (x40). c. Mitotic figures were high $(\times 400)$. d. Multinucleated cells were conspicuous $(\times 400)$. e. The tumor showed erythrocyte extravasation in the stroma $(\times 400)$. $\mathrm{f}$. In the scarce cell area, there were microcystic changes $(\times 100)$. 

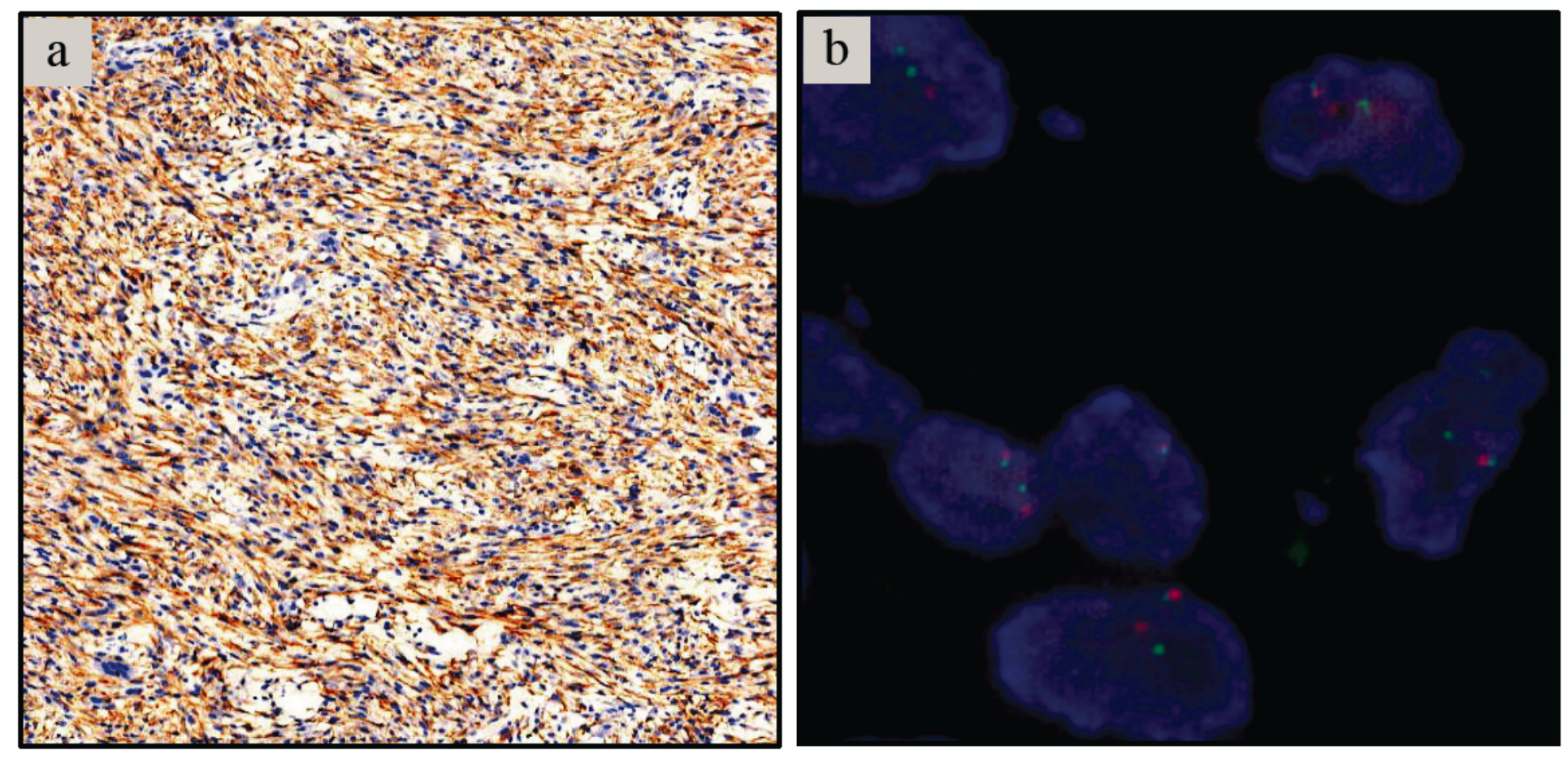

\section{Figure 3}

a. Immunohistochemical staining. Tumor cells were strongly immunoreactive for SMA. $(\times 100)$. b. FISH illustrated rearrangement of the USP6 gene locus 17p13 using a break-apart probe set, with separation of red and green signals.

\section{Supplementary Files}

This is a list of supplementary files associated with this preprint. Click to download.

- table1.pdf

- CAREchecklist.pdf 